\title{
NONLINEAR ARCHITECTURE AND MATHEMATICAL MODELING IN THE SYSTEM OF INTEGRATIVE LEARNING
}

\section{Lyubov Shchelkunova ${ }^{1}$ \\ Mariia Yemets ${ }^{2}$}

DOI: https://doi.org/10.30525/978-9934-588-15-0-64

\begin{abstract}
The article raised the issue of interdisciplinarity of the knowledge space of nonlinear architecture, among which mathematical methods and models are highlighted. The subject of research is the area of interaction between mathematics and nonlinear architecture in modern practice of architectural design in order to find approaches incorporating advanced mathematical knowledge in the educational process. Such work is the basis for integrative educational activities aimed at the implementation of intersubject communications. Statement of the problem. At present, such powerful areas of interdisciplinary knowledge, which are widely used in modern practice of architectural design, are not reflected in the programs of mathematical preparation of student architects. The research is aimed at eliminating the contradictions associated with the mismatch of the content of the mathematical education of students of architectural specialties with the requirements of modern architectural design. Materials and methods. The following methods were used in the work: collection, systematization, classification and generalization of information regarding the problem posed, a comparative analysis of different pedagogical approaches, synthesis and analysis of the results of one's own pedagogical integrative activity.Findings. The article substantiates that nonlinear architecture is interdisciplinary in nature and in this space one of the leading roles is played by mathematical methods and models. The field of basic mathematical methods and models used in modern nonlinear architecture is determined, among which the methods of fractal, geometric and parametric modeling are highlighted. The basic principles of fractal, geometric and parametric modeling of architectural objects are revealed and it is indicated that in many cases their fields of application intersect. This
\end{abstract}

\footnotetext{
${ }^{1}$ Associate Professor,

Kharkov National University of Construction and Architecture, Ukraine

${ }^{2}$ Candidate of Economic Sciences, Senior Lecturer,

Odessa National Academy of Food Technologies, Ukraine
}

(C) Lyubov Shchelkunova, Mariia Yemets 
nature of architectural activity justifies the need to create conditions for students to acquire interdisciplinary knowledge that meets the requirements of modern design. Authors propose to solve this problem on the basis of integrated technologies by developing and implementing special courses of applied orientation. The experience of such work indicates the necessity of combining the efforts of mathematicians, architects and IT specialists. As an alternative way to solve the problem, it is proposed to work within the framework of the student scientific society, and it is indicated that the experience of such activities demonstrates a positive result. The introduction of integrative forms of training provides the conditions for the acquisition of interdisciplinary knowledge, which is one of the key competencies of a modern specialist. This approach to the organization of the educational process contributes to its optimization.

\section{Introduction}

Formulation of the problem. For many centuries, architectural forms were defined (designed) in the language of geometry. Mathematical models describing geometric shapes laid the foundation for the formation of architectural forms. With the advent and development of computer science, the methods of shaping architectural objects also transformed. Modern computer methods for designing forms are based on the language of mathematical formulas and geometric constructions.

The term "nonlinear architecture" appeared at the end of the last century. The development of this direction is associated with the development of new dynamic principles of shaping, which are based on the mathematical paradigm of nonlinearity. The emergence of such a direction was facilitated by the development of both computer technologies and sciences of complex systems (sciences of complexity) such as fractal geometry, nonlinear dynamics, complexity theory (founder I. Prigogine), chaos (founder E. Lawrence), catastrophes, etc.

However, the presence in modern practice of architectural design of such powerful interdisciplinary areas of knowledge is practically not reflected in the educational process of students. The inclusion of this new relevant knowledge in educational programs based on integrative learning technologies could help to open up new opportunities for improving the quality of education for student architects. The relevance of such work is due to the direction to optimize the educational process by eliminating the contradictions associated with the mismatch of the content of mathematical educa- 
tion of students of architectural specialties with the requirements of modern architectural design [8, p. 212].

Analysis of relevant research. The development of "non-linear architecture", the formation of which dates back to the end of the twentieth century, was accompanied by modeling of various curved structures. Compared with classical architectural forms, in many cases these constructions were revealed to be more effective. It is, for example, to minimize consumables or increase the stability of the structure. Moreover, the modeling process is based on mathematical algorithms that underlie geometric, parametric, algorithmic and other design methods.

Today there are many publications related to the definition of the range of problems of architecture and urban planning, the solution of which is based on the use of mathematical methods and models. In these research, the term "architectural mathematics" appeared. However, the content and structure of this concept remain uncertain, since information on mathematical methods and models in architectural and urban planning is still fragmented [8, p. 214].

The inclusion of mathematical knowledge in the structure of architectural education is a complex, multifaceted and often contradictory system. In some universities, the teaching of higher mathematics is limited to a small basic course, the volume of which has been constantly decreasing in recent years. According to the authors, at present, in many universities, the volume of educational material included in the academic programs training discipline "Higher Mathematics" is completely insufficient, since it does not take into account new field of mathematics, the methods of which are used in modern practice of architectural design and urban planning.

The process of integration in education and science as a scientific concept appeared at the end of the last century, and is a leading trend in recent years. The goal of integration in education is to build such interconnections of the elements of the educational process that would create its completeness and integrity.

The relevance of the emergence of integrative pedagogical activity related to the concept of integration is based on the need to form personalities with polyphonic thinking as a condition for a deep understanding of the relationships in the processes of the world.

The tools for the implementation of integrative and pedagogical activities are integrative and pedagogical technologies, which are based on relevant concepts. 
There are different approaches to the classification of integrative activities in the education system. Among its main types (forms), it is possible to single out searches in the field of intrasubject and intersubject integration in order to optimize the educational process. The basis of such integrative and pedagogical activity is based on the concepts of intrasubject (V.I. Zagvyazinsky) and intersubject integration of pedagogical knowledge (founder John Dewey), integration of general and professional education (M.N. Berulova, Yu.S. Tyunnikov) etc.

A feature of intersubject integration is that it contributes to the organization of the educational process in which different academic disciplines interact, and intra-subject integration is also included in this activity.

The authors studied the experience of teaching higher mathematics in related universities. In some of them, teaching mathematical methods to student architects relies on the preservation of educational traditions with the updating of some blocks.

The experience of teaching higher mathematics at the Ural State Academy of Architecture and Art is interesting. Here, specialists from different fields interacted, which made it possible to solve problems in the analysis of architectural situations using mathematical methods. The main scientific and methodological direction is the development of new methods of teaching mathematics and computer disciplines in relation to the education of architects and designers [8, p. 212].

The aim of this research work is to study the field of interaction between mathematics and nonlinear architecture as a component of an integrative learning system (in the context of the application of mathematical methods and models in architectural and urban planning practice). Such work is the basis for integrative educational activities aimed at the implementation of intersubject communications. The authors define the following main objectives of the study:

1. Studying the experience of teaching higher mathematics to students of architectural specialties in related universities.

2 . The study of basic mathematical methods and models used in modern nonlinear architecture.

3. Identification of the basic principles of fractal, parametric and geometric modeling (based on the sciences of complex systems) when creating architectural objects.

4. Determination of approaches to introducing into the educational space of students of architectural specialties the interdisciplinary principle of teaching (in the context of teaching mathematical disciplines). 
The following methods were used in the article: collection, systematization, classification and generalization of information regarding the problem posed, a comparative analysis of different pedagogical approaches, synthesis and analysis of the results of one's own pedagogical integrative activity; generalized the results of domestic and foreign experience.

\section{Mathematical methods in nonlinear architecture}

Over the years, the authors have been searching for approaches to incorporating new mathematical knowledge into the training system for architects. The solution to this problem is carried out by developing elective courses designed for masters and senior students. Such special courses contain integration units of mathematical, computer and architectural knowledge.

A feature of this approach is the emphasis on the applied orientation of the content of educational material. In addition to the mathematical foundations of the corresponding theory, the thematic plan of the special course necessarily contains the main directions of the practical application of mathematical methods in architectural and urban planning practice.

The use of computer technology in shaping has led to the concept of digital architecture creating computational architectural objects. An analysis of the literature indicates the existence of different approaches to the description and systematization of computer modeling methods in nonlinear architecture. So, they distinguish such widely used methods in modern architectural practice as computer parametric, fractal, algorithmic, geometric modeling and their combinations. The applications of these methods often overlap due to the coincidence of the principles on which they are based.

All of the above demonstrates the interdisciplinary nature of modern architectural activity. Such a direction requires reflection in the educational process by creating conditions for the integrative activities of specialists in different fields.

\section{The method of geometric modeling in nonlinear architecture}

The method of geometric modeling in architectural and urban planning practice allows you to build a geometric object for the given properties and characteristics using computer programs. In modern design practice, many software packages are used (ArchiCAD, AutoCAD, Compass, Lira, MicroFe, ANSYS and others), however, the algorithms embedded in them sometimes require refinement for individual parameters. At the same time, the use of such universal mathematical software products as Mathematica, 
Maple, Mathlab, MathCAD, can lead to the construction of many different surfaces by changing the parameters of their analytical expression.

In nonlinear architecture, an important place is occupied by the algorithms of formation and transformation of the architectural form. The authors consider it necessary to search for opportunities for students to familiarize themselves with the mathematical foundations of geometric modeling. We are talking about analytical methods and algorithms for constructing mathematical models of surfaces and their scans (frames, shells, arches, etc.). However, in accordance with the existing programs of mathematical education of student architects, the only basis for such a study is school Euclidean and analytical geometry.

According to the authors, it is useful, interesting and important for students of architectural faculties to offer special courses on analytical surfaces that have found application in modern architectural and construction practice. The study of the variety and properties of such surfaces, in our opinion, can help future designers in the search for new forms in architecture. According to the famous architect and engineer E. Torroch, it is the form that ensures the reliability of the structure is the criterion of its quality.

There is reference and encyclopedic literature on the use of analytical surfaces in architectural and urban planning. However, a systematic review of the entire variety of surfaces used in various fields of activity (in particular, in architectural design) is implemented only in the book "Encyclopedia of Analytical Surfaces" (authors: Krivoshapko S., Ivanov V.).

This book is an encyclopedic publication on analytical and differential geometry of regular analytical surfaces, which have found application in various branches of mathematics and in various branches of engineering and construction $[4$, p. 3; p. 560]. The authors of the publication single out a large number of classes and subclasses of surfaces, among which in the basic course of the Higher Mathematics discipline for architectural specialties only second-order surfaces, cylindrical and rotation surfaces are considered. Important topics related to modeling surfaces of revolution are not included at all in the program, using as generators and guides not only simple geometric images (straight line, circular arc, ellipse, parabola, hyperbola), but also other arbitrary curves. And this approach provides unlimited possibilities in the shaping (for example, domes and arches), which contributes to the achievement of architectural expressiveness of structures [3, p. 80].

Outside the students' attention, there remain such surfaces common in architectural practice as chain, spiral, and higher-order surfaces. Also, elements of dif- 
ferential geometry are not included in the program of mathematical education, which means that the local properties of geometric objects remain unexplored.

The transformation of surfaces defined analytically can be carried out using both linear and non-linear transformations. Figure 1 provides the images of an ellipsoid obtained as a result of transformations given by different matrices [1, p. 106].

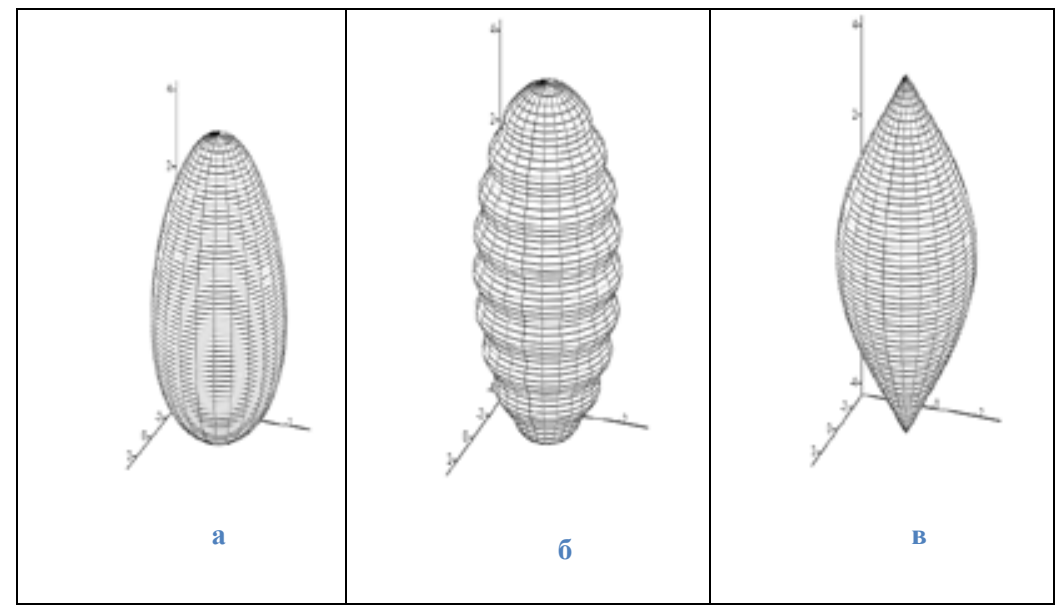

Figure 1. Transformations of an ellipsoid as a result of smooth nonlinear transformations [1, p. 108]

Interesting and useful are the issues of modeling composite structures, each element of which can be represented by different analytical expressions (Figure 2). Due to the capabilities of geometric modeling, these parts are combined using a group of affine transformations of motion, which include rotation and parallel translation transformations.

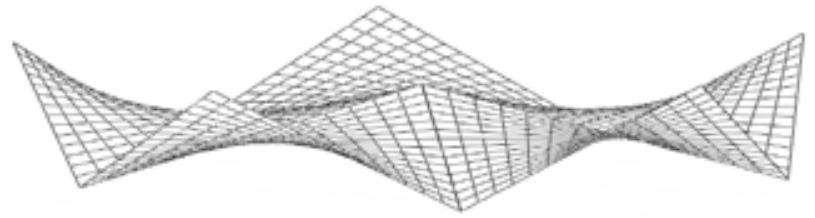

Figure 2. Composite surface of elements in the form of hypars [1, p. 112] 


\section{The method of fractal modeling in nonlinear architecture}

Among the relevant mathematical knowledge in architectural practice, we can distinguish fractal geometry methods, which today are becoming increasingly important in applied research. The main properties of fractal structures in architecture and urban planning include the following: self-similarity, ability to develop and move continuously, fractional dimension, manifestation of chaos and order at the same time.

It should be noted that fractal geometry is not included not only in the curriculum of the disciplines of the mathematical cycle, but also in the educational standards of training. And this means that future designers in the learning process at the university do not have the opportunity to acquire the basic foundations for using the fractal modeling method in future design activities.

To bridge this gap between mathematics-discipline and mathematics-science, the authors developed an integrated special course for undergraduates and master's degrees "Fractal Geometry and Architectural Design" $[9$, p. 66]. The structure and content of the author's program of the special course reflect the search for opportunities for students to acquire fractal construction skills using software tools. The authors expect that as a result of such work, future specialists will gain experience in modern types of activities and expand their capabilities in the field of creating various mathematical models in architectural design.

The program of the special course integrates knowledge blocks from fractal geometry, computer, in particular, fractal graphics, and the practice of architectural design. The problem of choosing integrative educational forms is associated with the construction of a model for establishing, primarily intersubject communications. Promising are the so-called previous connections, in which the lesson includes material previously studied in another discipline. In this case, concomitant relationships are established in which material from different disciplines is studied at the same time.

Table 1 presents the author's program of the integrated special course "Fractal Geometry and Architectural Design". The main objective of the course is the acquisition by students of skills in building fractals using software tools, which expands the possibilities of creating various mathematical models in architectural design and enriches them with the experience of modern activities.

A feature of the development of an integrated special course is the creation of software and methodological support: integrated universal envi- 
ronments, manuals, presentations. For example, to expand on the topic "Algorithms for constructing fractals", presentations were prepared on the topics "Building fractals using $L$-systems", "Building fractals on the complex plane", "Building fractals using affine transformations". When using $L$-systems, the "turtle-graphics" are used as output subsystems.

One of the main characteristics of fractal geometry is fractal dimension, which serves as a measure of the structure and self-similarity of an object. A fractal set fills space not as in the case of an ordinary geometric set, therefore, a fractal dimension is considered as a characteristic of the complexity of an object. In architecture, the consistency of the levels of fractal dimension of various elements of the object indicates the level of aesthetic expressiveness of the architectural structure: with an increase in consistency, the aesthetic value of the object increases.

To expand on the topic "Modeling fractal dimension", a presentation was prepared where different approaches to determining this characteristic are systematized, the main methods for its modeling are described, and examples of the use of fractal dimension analysis in architectural practice are presented [9, p. 67].

It is indicated that there are different approaches to determining the dimension. For mathematical fractals, these definitions are equivalent and differ only in the calculation algorithm. For the analysis of natural objects in architectural practice, they often use the point or cell method, the Hurst method (normalized scale method), the method of mass and informational dimension, the Grassberger-Proccaccio method and other numerical methods, since the use of a strict definition of fractal dimension is either impossible or may lead to inaccurate (and sometimes erroneous) results.

As described above, special attention in such integrative activities is paid to applied issues. The authors studied scientific papers related to the analysis of the use of fractal structures in architectural design. So, it's doctor of architecture S.B. Pomorov' opinion, that there are two ways to apply fractal structures in architectural design practice. The first way is associated with the use of well-known fractal models developed by famous scientists. Such structures include Sierpinski's napkin, Meger's sponge, Kanter's set, Koch curve, etc. For example, fractal structures in the form of a napkin and Sierpinski's triangle can be found in real design practice: works by Norman Foster (Hearst Tower), Kenzo Tange (Building Fuji TV headquarters on Odaiba Island) and others (Table 2). 
The program of the integrated special course

"Fractal analysis in architectural design"

\begin{tabular}{|c|c|c|}
\hline $\begin{array}{c}\text { № } \\
\text { lessons }\end{array}$ & Lesson topic & Using ICT Technology \\
\hline $1-2$ & Fractals and their properties & Presentation "Classification of fractals" \\
\hline $3-4$ & $\begin{array}{l}\text { Fractal Construction } \\
\text { Algorithms }\end{array}$ & $\begin{array}{c}\text { Presentations: } \\
\text { "The construction of fractals using } \\
\text { L-systems", } \\
\text { "The construction of fractals using affine } \\
\text { transformations", } \\
\text { "The construction of fractals on the } \\
\text { complex plane" }\end{array}$ \\
\hline $5-6$ & $\begin{array}{l}\text { Fractal modeling using } \\
\text { software }\end{array}$ & Maple, MathCAD, Math LAB \\
\hline $7-8$ & Fractal dimension modeling & $\begin{array}{c}\text { Presentation: } \\
\text { "Fractal dimension calculation methods" }\end{array}$ \\
\hline $9-10$ & Fractal Graphics Elements & $\begin{array}{c}\text { Editors: } \\
\text {-Painter, Art Dabbler - Fractal Explorer, } \\
\text { Chaos Pro. } \\
\text { Visual Studio } 2013\end{array}$ \\
\hline $11-12$ & $\begin{array}{l}\text { The use of fractal structures in } \\
\text { architectural practice }\end{array}$ & $\begin{array}{c}\text { Presentations: } \\
\text { "Protofractals", "Multifractals" }\end{array}$ \\
\hline $13-14$ & $\begin{array}{l}\text { Examples of computer fractal } \\
\text { models in architecture practice }\end{array}$ & \\
\hline
\end{tabular}

The modern architecture of buildings and structures, based on the use of quasifractals and multifractals (determined by several algorithms), demonstrates many different forms: from natural (drop-shaped, undulating) to completely bizarre.

The second way is to use the algorithm of natural systems in the created architectural project. This approach requires computer software for two purposes: firstly, to detect this algorithm in natural objects using computer analysis, and secondly, to use the algorithm in design [5, p. 80].

The emergence of mathematical models of cities with a dynamic structure as a complex self-organized system (a departure from static models) was the result of using the fractal principle of construction in urban planning. Since the "self-similarity" property in mathematical models is realized through recursive formulas, an unlimited number of similar fractal 
structures can be reproduced at any scale in each fractal. Such an approach to design assumes the existence of an interdisciplinary coordination of elements of the urban planning system.

Table 2

\section{Architectural examples of fractal structures}

(Patrik Schumacher, 2008)

\begin{tabular}{|c|c|c|}
\hline № & Fractal structures & Application examples \\
\hline & Sierpinski Triangle & $\begin{array}{c}\text { Hearst Tower-a building designed } \\
\text { by NormanFoster }\end{array}$ \\
\hline
\end{tabular}

The principles of fractal geometry have created new promising opportunities not only in modeling the urban environment, but also in the study of architectural compositions of buildings, which is especially valuable in relation to cultural heritage.

One of the main characteristics of fractal geometry is fractal dimension, which serves as a measure of the structure and self-similarity of an object. Fractal dimension is one way of determining the dimension of a set in metric space. One of the features of fractal dimension is its fractional value. For sets describing ordinary geometric shapes, the theoretical fractal dimension is equal to the usual Euclidean or topological dimension.

The scope of the fractal dimension analysis in modern architectural practice and urban planning includes the study of architectural monuments, which helps to reveal the specifics of their formation, identify new characteristics, adapt the experience of architecture of the past in modern architectural and urban planning (which contributes to the effective implementation of restoration work) [6, p. 14].

For example, at the Institute of Architecture and Design FSBEI HPE Altai State Technical University named after I.I. Polzunova, a fractal anal- 
ysis of 17 Islamic monuments located in different countries and created at different times was carried out [7, p. 144]. For the first time, a fractal compositional analysis of medieval cultural monuments was carried out: the Taj Mahal in India, the Sultan Ahmad mosque in Turkey, the Aljumma mosque in Iran, Tilla Kari Madrasah in Uzbekistan and others.

As a result of the research, a direct dependence of a high degree of fractality of Islamic architecture monuments and their artistic qualities was substantiated. Fractality was one of the most important means of revealing the compositional consistency of parts of buildings, as well as the unity of the structures of the architectural monument and the surrounding space.

In the analysis of the main projections of the Taj Mahal, the fractal dimension of the city plan, landscape plan, facade, section and ornament is high and is described by the following mathematical ratio $1<\mathrm{D}<2$. As a result of the comprehensive fractal analysis of the Taj Mahal, a high degree of fractal coordination was revealed at the urban and architectural levels. According to the authors, this gives one of the possible explanations for the integrity, unity, high artistic expressiveness of the Taj Mahal ensemble [7, p. 148].

Using fractal geometry methods, it is also possible to evaluate and predict planning structures at the city and agglomeration levels. Such an approach allows us to take into account the diversity and complexity of factors affecting the geometry of spatial phenomena, in contrast to urban planning models based on the laws of Euclidean geometry.

Active use of the fundamentals of fractal geometry in urban planning began in the late twentieth century and is continuing today. Fundamental work is now considered the work of P. Franckhauser (1998) and Betty and Longley (1994), where new principles for assessing the geometry, shape and structure of urban development objects were introduced.

Fractal analysis helps in the design of transport networks, a system for locating population densities, citywide subcenters, places of employment, etc. (Gushchina, 2016). This approach is designed to maximize the synergistic effect of the interaction of parts of the urban agglomeration.

\section{Parametric modeling method in architecture}

The parametric modeling method has long been widely used in architectural practice. This is due to the much greater opportunities that arise in the process of such an approach to design, in comparison with tradi- 
tional methods. Parametric modeling involves designing on the basis of a form self-organizing algorithm that takes into account the parameters of the model elements and their relationships. By varying the parameters, one can quickly get many different design solutions.

The basis of modern parametric modeling are BIM technologies. BIM (Building Information Modeling) is an information modeling of a building, the peculiarity of which is that the object is designed as a whole. Moreover, the simulated complex surfaces are based on mathematical models that include parametric equations.

Among the main techniques of the parametric method, meshing is distinguished. This grid is created through the points leaving it with the possibility of further transformation in various ways (extension, indentation, bending) and at the same time, any performed action is parameterized. For such techniques, there is MESH technology embedded in many software packages in which any form is generated through the category of nets. Such software environments include Corel Draw, Grasshopper, CATIA, 3D Max. In them, any shape can be transformed in tools such as Editable Mesh (Editable Surface), Creation Mesh (Create Surface) and change the shape by changing the coordinates and properties of each point on the surface. Complex forms can also be generated in the parametric method based on the use of heterogeneous rational B-splines (NURBS) and on the basis of portions of Bézier surfaces (Editable Patch) [2, p. 18].

It should be noted that in nonlinear architecture the concept of parametric design is becoming more widespread and may intersect with fractal design.

\section{Findings}

1. The necessity of bridging the gap between mathematics-discipline and mathematics-science in the context of the existing discrepancy between the content of the mathematical education of students of the architectural and urban specialty with the requirements of modern design is substantiated.

2. The interdisciplinary nature of nonlinear architecture is pointed out, the principles and rules of which are based on mathematical methods and models, which are becoming increasingly important in the design process. All this justifies the need to create conditions for students to obtain multidisciplinary knowledge through the introduction of integrated technologies. 
3. The field of basic mathematical methods and models used in modern nonlinear architecture is determined, the basic principles of fractal, geometric and parametric modeling of architectural objects are identified.

4. The limited nature of the presence of modern mathematical knowledge in existing educational programs is indicated and the possibilities of introducing this knowledge into the educational process are investigated.

5. The approaches aimed at the acquisition of interdisciplinary knowledge by future designers through the organization of scientific work in the framework of student scientific societies, as well as the introduction of specialized courses of applied orientation based on integrative technologies, are proposed.

\section{Conclusions}

Taking into account modern trends related to the strengthening of the interdisciplinary nature of the educational process, the joint efforts of mathematicians, architects, and IT specialists are necessary for the organic for implementation of mathematical knowledge into educational design.

The approach proposed in this paper to reduce the gap between mathematics and science and mathematical discipline in the process of training student architects requires the joint efforts of specialists in several fields, as well as coordination at different levels.

The process of creating and implementing any new educational course requires long and painstaking efforts. In addition to developing a thematic plan and methodological support for the discipline, the problem of finding opportunities to include a new course in the educational process arises.

The authors, as one of the possible directions for introducing new knowledge into the educational process of students of architectural specialties, offer work in the framework of the student scientific society. And the experience of such activities demonstrates a positive result. Students, having first become acquainted with the principles of fractal geometry, say that this new knowledge changes their whole understanding of the world. Also, according to the authors, it is advisable to carry out such work at the undergraduate level.

The authors believe that the need has long been ripe for revising the content of educational programs for students majoring in Architecture and Urban Planning. 
It should be noted that any new course should form an integral pedagogical system. The concept of creating special courses proposed in the article involves a review of approaches to the selection, placement of educational material, as well as the choice of teaching style, which is primarily associated with the applied orientation of such courses.

\section{References:}

1. Beljaeva Z.V. (2015). Geometricheskoe modelirovanie prostranstvennyh konstrukcij [Geometric modeling of spatial structures] (PhD Thesis). Yekaterinburg: UrFU named after the first president of Russia B.N. Yeltsin. (in Russian)

2. Volynskov Je.V. (2012). Informacionno-tehnologicheskie metody proektirovanija $\mathrm{v}$ arhitekturnom formoobrazovanii [Information and technological design methods in architectural shaping]. (PhD Thesis). Moscow: Moscow Architectural Institute. (in Russian)

3. Gushhina E.S., Smogunov V.V. (2016). Fraktal'naja razmernost' v ocenke planirovochnoj struktury krupnogo goroda [Fractal dimension in assessing the planning structure of a large city]. Sovremennye nauchnye issledovanija $i$ innovacii - Modern research and innovation, no. 2, pp. 110-116. Retrieved from: http://web.snauka.ru/issues/2016/02/63202 (in Russian)

4. Krivoshapko S.N., Ivanov V.N. (2010). Jenciklopedija analiticheskih poverhnostej [Encyclopedia of analytical surfaces]. Moskva: Knizhnyj dom "LIBROKOM". (in Russian)

5. Pomorov S.B., Ismail Haled D.A. (2014). Terminologija nelinejnoj arhitektury $i$ aspekty ejo primenenija [Terminology of nonlinear architecture and aspects of its application]. Vestnik TGASU - Bulletin TGASU, no. 3, pp. 78-87. (in Russian)

6. Patrik Schumacher (2008). Parametricism - A New Global Style for Architecture and Urban Design. AD Architectural Design - Digital Cities, vol. 79. No. 4, pp. 14-23

7. Ismail Haled D.A. (2013). Fraktal'nye postroenija v kompozicii arhitekturnyh ob"ektov (na primere pamjatnikov islamskoj arhitektury [Fractal structures in the composition of architectural objects (on the example of monuments of Islamic architecture)] (PhD Thesis). Barnaul: Altai State Technical University named after I.I. Polzunova. (in Russian)

8. Shchelkunova L.I., Shulhina S.S. (2011). Pro pidhodi do vdoskonalennja zmistu navchal'noï disciplini "Vishha matematika» dlja studentiv arhitekturnih special'nostej [About approaches to improving the content of the subject "Higher Mathematics" for students of architectural specialties]. Teorija ta metodika navchannja matematiki, fiziki, informatiki - Theory and methodology of teaching mathematics, physics, computer science, vol. 9, pp. 212-215. (in Ukrainian)

9. Shchelkunova L.I. (2017). Differencial'naja geometrija i fraktal'nyj analiz $\mathrm{v}$ arhitekturnom proektirovanii [Differential geometry and fractal analysis in architectural design]. Proceedings of the International Scientific and Practical Conference: Science in the 21st Century: Challenges and Prospects for Development (April 28). Voronezh: Research, pp. 63-69. (in Russian) 